\title{
Testing Texture of VHR Panchromatic Data as a Feature of Land Cover Classification
}

\author{
Stanisław LEWIŃSKI, Sebastian ALEKSANDROWICZ, \\ and Marek BANASZKIEWICZ
}

\begin{abstract}
Space Research Centre, Polish Academy of Sciences, Warszawa, Poland; e-mails: stlewinski@cbk.waw.pl (corresponding author), saleksandrowicz@cbk.waw.pl,marekb@cbk.waw.pl
\end{abstract}

\begin{abstract}
While it is well-known that texture can be used to classify very high resolution (VHR) data, the limits of its applicability have not been unequivocally specified. This study examines whether it is possible to divide satellite images into two classes associated with "low" and "high" texture values in the initial stage of processing VHR images. This approach can be effectively used in object-oriented classification. Based on the panchromatic channel of KOMPSAT-2 images from five areas of Europe, datasets with down-sampled pixel resolutions of 1, 2, 4, 8, and $16 \mathrm{~m}$ were prepared. These images were processed using different texture analysis techniques in order to discriminate between basic land cover classes. Results were assessed using the normalized feature space distance expressed by the Jeffries-Matusita distance. The best results were observed for images with the highest resolution processed by the Laplacian filter. Our research shows that a classification approach based on the idea of "low" and "high" textures can be effectively applied to panchromatic data with a resolution of $8 \mathrm{~m}$ or higher.
\end{abstract}

Key words: object-oriented classification, land cover classification, texture, Laplacian filter. 


\section{INTRODUCTION}

Texture is expressed by the frequency of tonal values (brightness or colour) of neighbouring points of an image and is one of the most important features for the interpretation of data gathered through remote sensing. In visual classification, texture is as important as the tone, shape, and size of the identified object. This is also the case in automatic classification, which is based on the digital numbers of pixels that make up an image (Tuceryan and Jain 1999). Image processing systems for the interpretation of satellite data have functions for the calculation of texture parameters such as: variance, contrast, entropy, homogeneity or correlation. The spatial extent of the analyses is determined by the size of the moving window. Computations are usually performed on square windows of $3 \times 3$ or $5 \times 5$ pixels and the resulting value is output to a layer that corresponds to the position of the window's central pixel.

More complex calculations are based on the Grey Level Co-occurrence Matrix (GLCM). With this method, texture can be determined not only within a pre-defined window, but also for an object of any shape. The first step is to make the co-occurrence matrix symmetrical around the diagonal. Then it is normalized and at this point it represents the probability of occurrence of data values. Next, it is processed in order to describe the texture of the object (Hall-Beyer 2000). Based on the GLCM, Haralick et al. (1973) proposed 14 features for image classification. Another method of determining texture is to use image filtration methods. Although these are usually based on the moving window technique, their goal is not specifically to measure texture but rather to increase and highlight it. There are many different high pass and edge detection filters (including adaptive statistical filters) that can be used for this purpose. Similarly, filters that smooth the image by removing anomalies can be applied to highlight textural features.

Texture plays a particularly important role in object-oriented algorithms (Blaschke 2010). In contrast to traditional pixel-based approaches, these algorithms work at the level of entire objects rather than individual pixels. Objects are formed through a segmentation process that groups pixels that meet given similarity conditions. Objects can be then analysed on the basis of a variety of distinctive features, including texture. The computation of the texture of the area identified as the object is based on spectral channels processed by texture functions or filters. Haralic functions are implemented in object-oriented software such as eCognition (eCognition Developer 2011) and are often used despite very time-consuming calculations. Texture is applied not only for class identification but also as an additional data source for image segmentation (Ryherd and Woodcock 1996, Hofmann et al. 1998, Hu et al. 2005). 
Textural features are mainly applied in order to identify built-up areas on VHR satellite images. GLCM parameters are used to discriminate urban and non-urban areas and to extract urban areas from other land cover classes (De Martinao et al. 2003, Morales et al. 2003, Puissant et al. 2005, Wang et al. 2003, He et al. 2005, Su et al. 2008, Lewinski and Bochenek 2009). Kit et al. (2012) used VHR satellite images to identify informal settlements. De Kok (2012) proposed the simulation of a large $49 \times 49$ Laplacian filter for testing neighbourhood contrast in order to enhance the detection of artificial areas. Esch et al. (2010) provide examples of urban classification based on the analysis of the texture of synthetic aperture radar (SAR) images. Berberoglu et al. (2007) assessed usefulness of texture measures for maximum likelihood and artificial neural networks classification routines. They tested texture measures calculated for three different windows $(3 \times 3,5 \times 5$, $7 \times 7$ ) over the Landsat TM image of Mediterranean area. Textural analysis is not only useful for typical land cover classification; other examples are forest biomass estimation (Eckert 2012) or the classification of sub-Antarctic vegetation (Murray et al. 2010).

The algorithm proposed by De Kok and Wezyk (2008) was based on the hypothesis that it is possible to divide an image into so-called "low" and "high" textures from calculations based on high-resolution panchromatic channels. Low texture values are associated with agricultural land and bodies of water. Other land cover classes (primarily various species of forests and built-up areas) are characterized by higher texture. The strategy is based on a sequential classification - from general to more detailed. The division into two textural groups is very helpful because the algorithm can be targeted at the initial stage of the classification. In general, it can be assumed that once all the water bodies have been identified, agricultural land (the most complex land cover class) will be "automatically" recognized because it belongs to the rest of the "low" texture area. Other land cover classes belong to high texture areas and are classified in separate processes. A simplified work-flow is presented in Fig. 1.

A threshold value between low and high textures can be defined interactively using designated sets of training fields for agricultural areas, water bodies, forests, and buildings. De Kok and Wezyk (2008) proposed using the distribution of histogram quantiles to express the threshold value. Similarly, Nussbaum et al. (2006) developed statistical tools to determine the threshold (the crossing point) between the distributions of textures in sets of training fields.

The idea of initializing the classification using "low" and "high" textures was implemented in the SATChMo-K2 algorithm. The algorithm was developed as one of the Core Mapping Services of the Geoland2 project SATChMo (Seasonal and Annual Change Monitoring). The Area Frame Sam- 


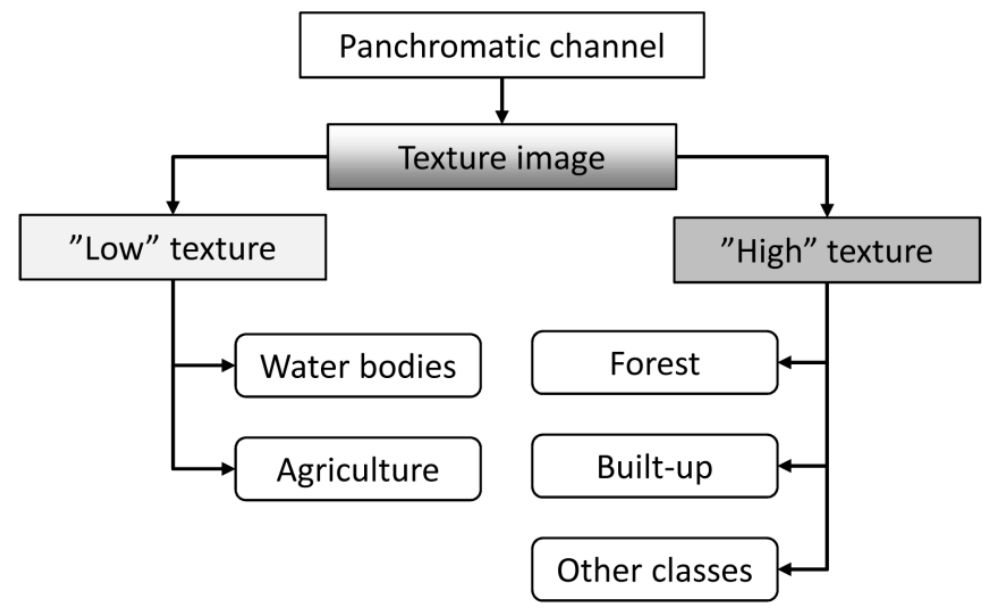

Fig. 1. Land cover classification work-flow based on assumptions of "low" and "high" texture.

pling Europe (AFS Europe) subproject generated generic maps of land cover. This approach was designed for the classification of KOMPSAT-2 and FORMOSAT-2 VHR satellite images (Lewinski et al. 2014). Texture was calculated based on panchromatic channels processed by sigma filters. The algorithm has also been used to generate land cover maps based on other VHR datasets (Ikonos, QuickBird, and SPOT). The use of texture as a basic classifier made it possible to achieve similar results irrespective of the season (spring, summer or autumn) and to use the same classification features for images of similar European regions.

The project ran extensive experiments. Seven teams classified the basic land cover classes of more than 120 images scattered across Europe. This work showed that the classification approach is sensitive to spatial resolution. Both KOMPSAT-2 and FORMOSAT-2 images belong to the group of VHR data, but the spatial resolution of KOMPSAT-2 (PAN - $1 \mathrm{~m}$, MS $4 \mathrm{~m}$ ) is four times better than that of FORMOSAT-2 (PAN $-2 \mathrm{~m}$, MS $8 \mathrm{~m})$; it is therefore easier to divide KOMPSAT-2 images into "low" and "high" textures. Moreover, the effectiveness of the algorithm depended on the geographic area. The most difficult area to classify was Southern Europe, especially Spain. This was mainly due to dispersed vegetation, and not seasonal differences.

The work of the SATChMo team forms the basis for the study described here. The initial texture-based classification was a crucial step and more insight is needed into the correct selection of textural parameters. Parameter selection mainly depends on the sensor resolution and the geographic loca- 
tion. The aim of this study was therefore to determine whether it would be possible to use the "low" and "high" texture classification approach for the panchromatic images of different spatial resolution.

\section{SATELLITE DATA AND TEXTURE PREPROCESSING}

The work was performed using KOMPSAT-2 satellite images provided by the European Space Agency (ESA), which were intended for land cover classification in the context of the SATChMo project. Five images were selected from over one hundred datasets, scattered across Europe. They included typical types of land cover found in central, northern, and southern Europe. Analyses were performed on a subset of panchromatic data defined for each image. The selected images are specified in Table 1 and shown in Fig. 2. The Spanish image was representative of the Mediterranean countries; it was included because of the difficulty of classifying this type of land cover. The selected image subsets do not have an equal area. This is because we were trying to find image fragments that included all types of land cover.

Table 1

Selected subsets of satellite images

\begin{tabular}{|c|c|c|c|c|c|c|}
\hline No. & Satellite data & $\begin{array}{c}\text { Date of } \\
\text { acquisition }\end{array}$ & 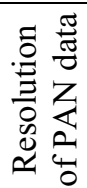 & $\begin{array}{c}\text { Coordinates } \\
\text { of a subset } \\
\text { (centre) } \varphi, \lambda\end{array}$ & Country & $\begin{array}{l}\text { Area } \\
{\left[\mathrm{km}^{2}\right]}\end{array}$ \\
\hline 1 & KOMPSAT-2 & 10 Sep 2009 & $1 \mathrm{~m}$ & $\begin{array}{l}52^{\circ} 10^{\prime} 18.6^{\prime \prime} \mathrm{N} \\
17^{\circ} 24^{\prime} 02.8^{\prime \prime} \mathrm{E}\end{array}$ & Poland & 85.5 \\
\hline 2 & KOMPSAT-2 & 19 Sep 2009 & $1 \mathrm{~m}$ & $\begin{array}{r}53^{\circ} 44^{\prime} 31.8^{\prime \prime} \mathrm{N} \\
8^{\circ} 40^{\prime} 20.0^{\prime \prime} \mathrm{E}\end{array}$ & Germany & 73.0 \\
\hline 3 & KOMPSAT-2 & 9 Aug 2009 & $1 \mathrm{~m}$ & $\begin{array}{l}63^{\circ} 40^{\prime} 25.5^{\prime \prime} \mathrm{N} \\
26^{\circ} 31^{\prime} 30.3^{\prime \prime} \mathrm{E}\end{array}$ & Finland & 83.0 \\
\hline 4 & KOMPSAT-2 & $21 \mathrm{Jul} 2009$ & $1 \mathrm{~m}$ & $\begin{array}{r}45^{\circ} 05^{\prime} 55.2^{\prime \prime} \mathrm{N} \\
0^{\circ} 46^{\prime} 12.0^{\prime \prime} \mathrm{W}\end{array}$ & France & 70.8 \\
\hline 5 & KOMPSAT-2 & 26 Aug 2009 & $1 \mathrm{~m}$ & $\begin{array}{c}43^{\circ} 19^{\prime} 41.3^{\prime \prime} \mathrm{N} \\
4^{\circ} 06^{\prime} 55.6^{\prime \prime} \mathrm{W}\end{array}$ & Spain & 91.7 \\
\hline
\end{tabular}

Lower-resolution images were simulated using the $1 \mathrm{~m}$ resolution panchromatic channel of KOMPSAT-2. We applied the "degradation" function of the ERDAS Imagine software and generated images with pixel sizes of 2, 4,8 , and $16 \mathrm{~m}$. Using this technique, a panchromatic dataset of $1-16 \mathrm{~m}$ resolution was collected for each test area. Figure 3 shows subsets at resolutions of 1 and $8 \mathrm{~m}$. 


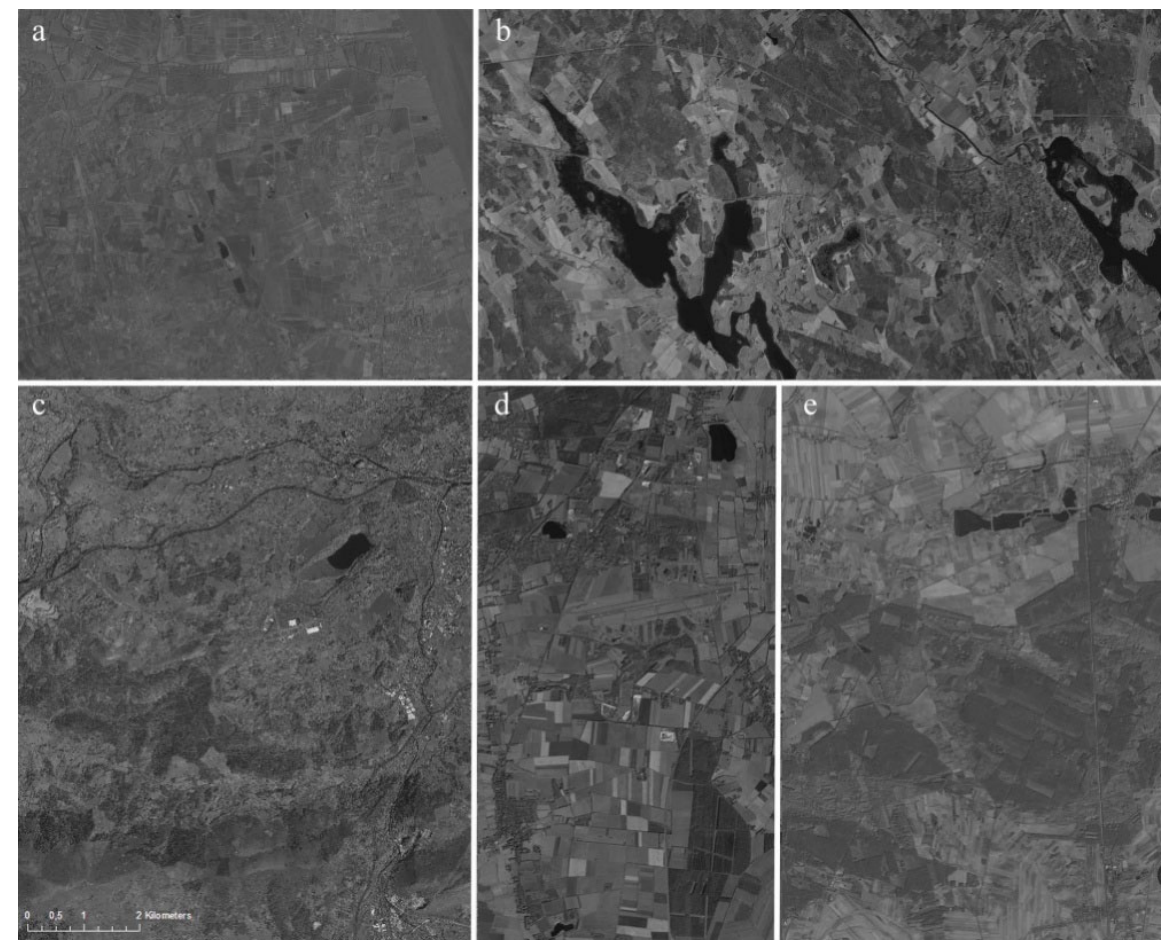

Fig. 2. Selected subsets of satellite images: (a) France, (b) Finland, (c) Spain, (d) Germany, and (e) Poland.

(a)

(b)

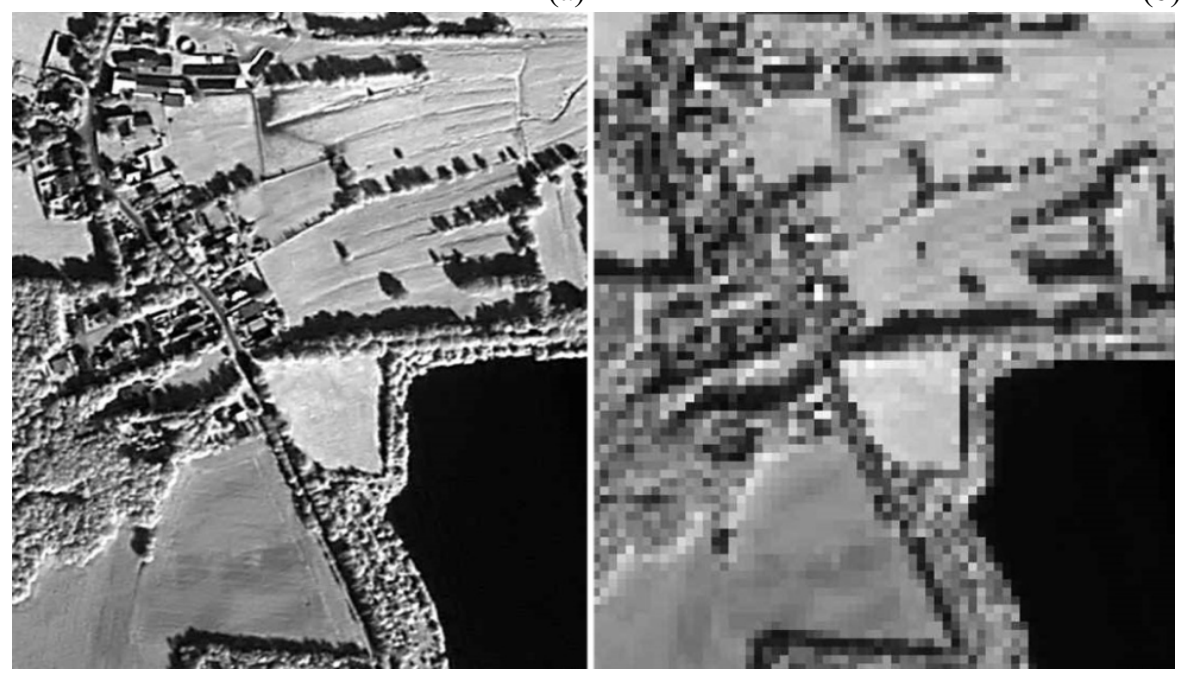

Fig. 3. Panchromatic channel of KOMPSAT-2 image at $1 \mathrm{~m}$ (a) and $8 \mathrm{~m}$ (b) resolution (German test site). 
In order to obtain textural information, panchromatic channels were processed using six image texture analysis techniques: the PanBF transformation, the sum of two Lee Sigma filters, the Sobel filter, the Laplacian filter, Gray-Level Co-occurrence Matrix (GLCM) homogeneity, and GLCM entropy. These functions were selected because they are the most useful for land cover classification based on the SATChMo-K2 algorithm.

The PanBF transformation was proposed by Wezyk and De Kok (2006). It is the ratio of panchromatic data and the sum of two edge-detection images processed inside a $3 \times 3$ moving window by the Lee Sigma filter:

$$
\text { PanBF }=\frac{\text { PAN }}{\text { LeeSigma }+ \text { LeeSigma } n},
$$

where PanBF is the PanBF transformation, PAN is panchromatic data, LeeSigma is panchromatic data processed using the Lee Sigma filter, LeeSigma_ $n$ is inversed (negative) panchromatic data processed using the Lee Sigma filter.

The Lee Sigma filter first computes a mean and standard deviation for a given window. Next the number of pixels that satisfy the criteria defined by the sigma value is tested and the output is calculated based on this value (Jensen 1996).

The second feature texture test also used the Lee Sigma filter. This is a sum of two Lee Sigma filters and it was applied in the SATChMo-K2 algorithm. eCognition software was used to calculate the sum of Lee Sigma filters with "dark" and "bright" options (eCognition Developer 2011). Edge detection was performed inside a moving $3 \times 3$ window for dark and bright objects, respectively. Results were similar to LeeSigma and LeeSigma_ $n$.

$$
\text { Sum_Sigma }=\text { LeeSigma }(\text { dark })+\text { LeeSigma }(\text { bright }) \text {, }
$$

where Sum_Sigma is the sum of Lee Sigma filters, LeeSigma is panchromatic data processed using eCognition's Lee Sigma filter with "dark" and "bright" options.

The Sobel filter is an edge detection filter. The output value is computed based on two $3 \times 3$ kernels (Jain 1989):

$$
\text { Sobel }=\sqrt{X^{2}+Y^{2}},
$$

where $X$ and $Y$ represent the convolution mask:

$$
\begin{array}{rrrrrc}
-1 & 0 & 1 & 1 & 2 & 1 \\
-2 & 0 & 2 & Y=0 & 0 & 0 \\
-1 & 0 & 1 & -1 & -2 & -1
\end{array}
$$


Laplacian filters were designed for edge enhancement (Jensen 1996). Image processing is based on elements of the convolution mask. The $3 \times 3$ mask that was applied is presented below:

$$
\begin{aligned}
& \begin{array}{lll}
0 & -1 & 0
\end{array} \\
& \text { Laplacian mask }=-1 \quad 4 \quad-1 \text {. } \\
& \begin{array}{lll}
0 & -1 & 0
\end{array}
\end{aligned}
$$

GLCM texture functions were proposed by Haralick et al. (1973) and they are regularly used in object-oriented classification. Homogeneity and entropy were selected from among the various GLCM functions because they are not well correlated. The calculation consists of two steps. First, the co-occurrence matrix is defined based on the pixels that make up the object, and then this matrix is transformed using the following expressions:

$$
\begin{gathered}
\text { Homogenity }=\sum_{i, j}^{n} \frac{c_{i, j}}{1+(i-j)^{2}}, \\
\text { Entropy }=\sum_{i . j}^{n} C_{i, j} * \log \left(C_{i, j}\right),
\end{gathered}
$$

where $C$ is the co-occurrence matrix; $n, i$, and $j$ are the dimensions and elements of the matrix $C$.

Two examples of texture images are presented in Fig. 4. They were obtained from the image subsets shown in Fig. 3 with resolutions of 1 and $8 \mathrm{~m}$, processed by a Laplacian filter.

(a)

(b)

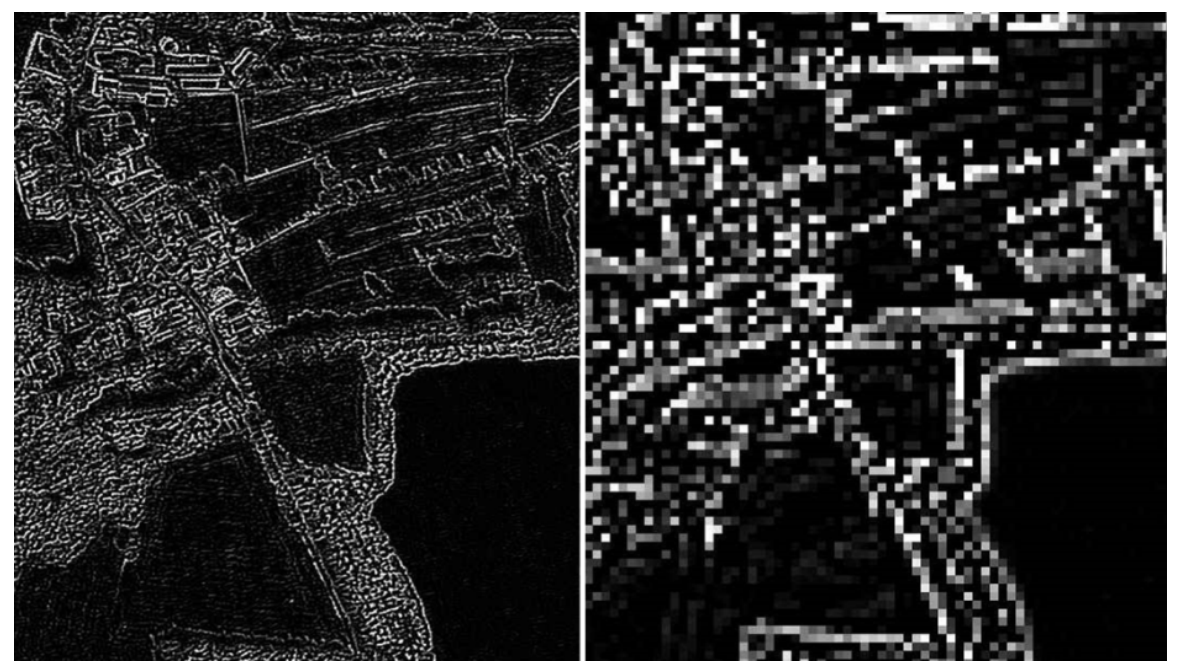

Fig. 4. Panchromatic channel processed by a Laplacian $3 \times 3$ filter; $1 \mathrm{~m}$ (a) and $8 \mathrm{~m}$ (b) resolution (German test site). 


\section{CLASS SEPARATION}

The aim of the analysis was to determine the ability of the various texture measurement functions to define the threshold between "low" and "high" texture. The functions were tested on panchromatic data at different resolutions. For each of the images, training sets of four basic land cover classes were selected: water bodies, agricultural areas, forest and built-up areas. Next, we calculated separation measures between land cover classes based on texture. It is usually assumed that "water" and "agricultural areas" are associated with low values of texture while "forest" and "built-up areas" are associated with high values. For the Spanish image, a new class called "shrubland" was included in the analysis in order to represent the dispersed vegetation that occurs in the South of Europe.

Analyses were based on an object-oriented classification and the objects to be analysed were defined in the segmentation process. The segmentation procedure depends on the type of data (its spectral, spatial, and radiometric resolution) and the Earth's land cover structure. As segmentation defines the shapes of objects, it strongly influences the classification results. A "chessboard" segmentation was applied; this was both to avoid the complex process of finding optimal segmentation parameters for each case and also to minimize the impact of segmentation on the final results. Consequently, each image was divided into a square object measuring $128 \times 128 \mathrm{~m}$. Next, objects that were completely filled with one of the chosen land cover classes were selected as training sets. This process was made possible by the results of the land cover classification performed in the context of the SATChMo project.

The extent of class discrimination was determined using the JeffriesMatusita (J-M) distance. The J-M distance is a widely-used measure for feature selection. Calculations were based on the Bhattacharyya distance, which was defined assuming that the distributions of the analysed classes were Gaussian. Jensen (1996) provides the following formulas:

$$
\text { Bhat }_{c d}=\frac{1}{8}\left(M_{c}-M_{d}\right)^{T}\left(\frac{V_{c}+V_{d}}{2}\right)^{-1}\left(M_{c}-M_{d}\right)+\frac{1}{2} \ln \left[\frac{\left|\frac{V_{c}+V_{d}}{2}\right|}{\sqrt{\left|V_{c}\right|\left|V_{d}\right|}}\right],
$$

where Bhat ${ }_{c d}$ is the Bhattacharyya distance between classes $c$ and $d, M_{c}$ and $M_{d}$ are the means of classes $c$ and $d, V_{c}$ and $V_{d}$ are the covariance matrices of classes $c$ and $d$.

$$
\mathrm{JM}_{c d}=\sqrt{2\left(1-e^{\text {Bhat }_{c d}}\right)},
$$

where $\mathrm{JM}_{c d}$ is the Jeffries-Matusita distance between classes $c$ and $d$. 
The spectral separability can be described by the squared J-M distance and in this case the values are squared to range between 0 and 2 .

\section{RESULTS}

Our work aimed to determine the possibility of dividing images into "low" and "high" texture values. We calculated the J-M distance between pairs of land cover (LC) classes: water, agricultural areas, forest, and built-up areas. Five test sites in Poland, Germany, Finland, France, and Spain were analysed. For each site, six textures obtained from panchromatic data with resolution $1,2,4,8$, and $16 \mathrm{~m}$ were analysed. Results were obtained for a total of 150 cases. The full set of results for the German test image is presented in Tables 2-6. These tables show the J-M distances for different image resolutions. Columns represent texture features, while rows list pairs of land cover classes. Similar results were obtained for test sites in Poland, Finland, and France. The results were a little different for the Spanish test site, and they are presented in Tables 7-11.

We assumed that two classes were completely separate if the squared $\mathrm{J}-\mathrm{M}$ distance was 2, while a value of 1.4 or less indicated potential overlapping of classes (Intergraph 1999). Thomas et al. (2003) defined good and poor separability for squared J-M distances as $>1.9$ and $<1.0$, respectively. We assumed that it was possible to define the threshold between "low" and "high" texture if the value was over 1.7, and these values are marked bold in the tables that follow.

In Tables 12-16 the squared J-M distances are calculated for the combined classes: (i) "water bodies" and "agricultural areas", and (ii) "forest" and "built-up areas". Information about the separation of overlapping classes is particularly important from the point of view of the definition of the threshold between low and high texture. Like the previous tables, results are divided according to spatial resolution $(1,2,4,8$, and $16 \mathrm{~m})$, and values over 1.7 are highlighted in bold.

As expected, the most promising results - indicating the ability to divide an image into low and high textures - were obtained with a resolution of $1 \mathrm{~m}$ (Table 12). This classification was possible for images from Poland, Germany, Finland, and France. Almost identical results were obtained using Laplace and Sum_Sigma filtration. Sobel filtering made it possible to obtain slightly better results for images from Germany and Finland, slightly worse for Poland and much worse for France. However, for the Spanish image the $\mathrm{J}-\mathrm{M}$ distances indicated that distinguishing between low and high texture was impossible.

The results shown in Table 13 for a $2 \mathrm{~m}$ resolution are similar to those shown previously. The Sum_Sigma and Laplace filters performed best, while the Sobel filter did not perform as well. Other transformation tech- 
Table 2

PAN data $-1 \mathrm{~m}$, Germany. Squared J-M distance between basic LC classes

\begin{tabular}{|l|c|c|c|c|c|c|}
\hline \multirow{2}{*}{ Land cover classes } & \multicolumn{7}{|c|}{ Texture functions } \\
\cline { 2 - 7 } & PanBF & $\begin{array}{c}\text { Laplace } \\
3 \times 3\end{array}$ & Sobel & $\begin{array}{c}\text { Sum_- } \\
\text { Sigma }\end{array}$ & $\begin{array}{c}\text { GLCM } \\
\text { homo- } \\
\text { geneity }\end{array}$ & $\begin{array}{c}\text { GLCM } \\
\text { entropy }\end{array}$ \\
\hline agriculture/forest & $\mathbf{1 . 7 8}$ & $\mathbf{1 . 9 1}$ & $\mathbf{1 . 9 6}$ & $\mathbf{1 . 9 1}$ & 1.24 & $\mathbf{1 . 7 8}$ \\
forest/built-up & 0.14 & 0.09 & 0.22 & 0.09 & 1.26 & 0.56 \\
built-up/water & $\mathbf{2 . 0 0}$ & $\mathbf{2 . 0 0}$ & $\mathbf{2 . 0 0}$ & $\mathbf{2 . 0 0}$ & $\mathbf{1 . 9 4}$ & $\mathbf{2 . 0 0}$ \\
agriculture/built-up & $\mathbf{1 . 7 2}$ & $\mathbf{1 . 9 7}$ & $\mathbf{1 . 9 9}$ & $\mathbf{1 . 9 7}$ & 0.71 & $\mathbf{1 . 7 4}$ \\
forest/water & $\mathbf{2 . 0 0}$ & $\mathbf{2 . 0 0}$ & $\mathbf{2 . 0 0}$ & $\mathbf{2 . 0 0}$ & $\mathbf{1 . 9 9}$ & $\mathbf{2 . 0 0}$ \\
agriculture/water & 1.34 & $\mathbf{2 . 0 0}$ & $\mathbf{2 . 0 0}$ & $\mathbf{2 . 0 0}$ & 0.46 & 1.58 \\
\hline
\end{tabular}

Table 3

PAN data $-2 \mathrm{~m}$, Germany. Squared J-M distance between basic LC classes

\begin{tabular}{|l|c|c|c|c|c|c|}
\hline \multirow{2}{*}{ Land cover classes } & \multicolumn{7}{|c|}{ Texture functions } \\
\cline { 2 - 7 } & PanBF & $\begin{array}{c}\text { Laplace } \\
3 \times 3\end{array}$ & Sobel & $\begin{array}{c}\text { Sum_- } \\
\text { Sigma }\end{array}$ & $\begin{array}{c}\text { GLCM } \\
\text { homo- } \\
\text { geneity }\end{array}$ & $\begin{array}{c}\text { GLCM } \\
\text { entropy }\end{array}$ \\
\hline agriculture/forest & 1.69 & $\mathbf{1 . 9 5}$ & $\mathbf{1 . 9 5}$ & $\mathbf{1 . 9 4}$ & 1.37 & $\mathbf{1 . 7 5}$ \\
forest/built-up & 0.18 & 0.11 & 0.82 & 0.14 & 1.13 & 0.15 \\
built-up/water & $\mathbf{2 . 0 0}$ & $\mathbf{2 . 0 0}$ & $\mathbf{2 . 0 0}$ & $\mathbf{2 . 0 0}$ & $\mathbf{2 . 0 0}$ & $\mathbf{2 . 0 0}$ \\
agriculture/built-up & 1.63 & $\mathbf{1 . 9 9}$ & $\mathbf{2 . 0 0}$ & $\mathbf{1 . 9 8}$ & 0.92 & $\mathbf{1 . 7 7}$ \\
forest/water & $\mathbf{2 . 0 0}$ & $\mathbf{2 . 0 0}$ & $\mathbf{2 . 0 0}$ & $\mathbf{2 . 0 0}$ & $\mathbf{2 . 0 0}$ & $\mathbf{2 . 0 0}$ \\
agriculture/water & 1.00 & $\mathbf{2 . 0 0}$ & $\mathbf{2 . 0 0}$ & $\mathbf{2 . 0 0}$ & 0.43 & 1.56 \\
\hline
\end{tabular}

Table 4

PAN data - 4 m, Germany. Squared J-M distance between basic LC classes

\begin{tabular}{|l|c|c|c|c|c|c|}
\hline \multirow{2}{*}{ Land cover classes } & \multicolumn{7}{|c|}{ Texture functions } \\
\cline { 2 - 7 } & PanBF & $\begin{array}{c}\text { Laplace } \\
3 \times 3\end{array}$ & Sobel & $\begin{array}{c}\text { Sum_- } \\
\text { Sigma }\end{array}$ & $\begin{array}{c}\text { GLCM } \\
\text { homo- } \\
\text { geneity }\end{array}$ & $\begin{array}{c}\text { GLCM } \\
\text { entropy }\end{array}$ \\
\hline agriculture/forest & 1.62 & 1.92 & 1.54 & 1.89 & 1.50 & 1.64 \\
forest/built-up & 0.03 & 0.84 & 1.78 & 0.98 & 0.70 & 0.77 \\
built-up/water & 2.00 & 2.00 & 2.00 & 2.00 & 2.00 & 2.00 \\
agriculture/built-up & 1.61 & 2.00 & 2.00 & 1.99 & 1.24 & 1.80 \\
forest/water & 2.00 & 2.00 & 2.00 & 2.00 & 2.00 & 2.00 \\
agriculture/water & 1.34 & 2.00 & 1.97 & 2.00 & 0.39 & 1.32 \\
\hline
\end{tabular}


Table 5

PAN data $-8 \mathrm{~m}$, Germany. Squared J-M distance between basic LC classes

\begin{tabular}{|l|c|c|c|c|c|c|}
\hline & \multicolumn{6}{|c|}{ Texture functions } \\
\cline { 2 - 7 } Land cover classes & PanBF & $\begin{array}{c}\text { Laplace } \\
3 \times 3\end{array}$ & Sobel & $\begin{array}{c}\text { Sum } \\
\text { Sigma }\end{array}$ & $\begin{array}{c}\text { GLCM } \\
\text { homo- } \\
\text { geneity }\end{array}$ & $\begin{array}{c}\text { GLCM } \\
\text { entropy }\end{array}$ \\
\hline agriculture/forest & 1.42 & 1.33 & 0.39 & 1.17 & 1.49 & 1.25 \\
forest/built-up & 0.53 & 1.72 & 1.68 & 1.77 & 0.01 & 1.46 \\
built-up/water & 2.00 & 2.00 & 2.00 & 2.00 & 1.98 & 2.00 \\
agriculture/built-up & 1.56 & 1.99 & 1.93 & 1.99 & 1.46 & 1.80 \\
forest/water & 2.00 & 1.99 & 1.68 & 1.98 & 1.98 & 2.00 \\
agriculture/water & 1.26 & 1.93 & 1.38 & 1.91 & 0.41 & 0.78 \\
\hline
\end{tabular}

Table 6

PAN data $-16 \mathrm{~m}$, Germany. Squared J-M distance between basic LC classes

\begin{tabular}{|l|c|c|c|c|c|c|}
\hline \multirow{2}{*}{ Land cover classes } & \multicolumn{6}{|c|}{ Texture functions } \\
\cline { 2 - 7 } & PanBF & $\begin{array}{c}\text { Laplace } \\
3 \times 3\end{array}$ & Sobel & $\begin{array}{c}\text { Sum- } \\
\text { Sigma }\end{array}$ & $\begin{array}{c}\text { GLCM } \\
\text { homo- } \\
\text { geneity }\end{array}$ & $\begin{array}{c}\text { GLCM } \\
\text { entropy }\end{array}$ \\
\hline agriculture/forest & 0.70 & 0.33 & 0.09 & 0.24 & 1.08 & 0.58 \\
forest/built-up & 0.58 & 1.56 & 0.71 & 1.55 & 0.64 & 1.14 \\
built-up/water & 2.00 & 2.00 & 1.73 & 2.00 & 1.92 & 2.00 \\
agriculture/built-up & 1.27 & 1.85 & 0.50 & 1.81 & 1.48 & 1.54 \\
forest/water & 2.00 & 1.49 & 0.77 & 1.54 & 1.87 & 1.97 \\
agriculture/water & 0.50 & 1.20 & 0.36 & 1.18 & 0.50 & 0.30 \\
\hline
\end{tabular}

Table 7

PAN data $-1 \mathrm{~m}$, Spain. Squared J-M distance between basic LC classes

\begin{tabular}{|l|c|c|c|c|c|c|}
\hline \multirow{2}{*}{ Land cover classes } & \multicolumn{6}{|c|}{ Texture functions } \\
\cline { 2 - 7 } & PanBF & $\begin{array}{c}\text { Laplace } \\
3 \times 3\end{array}$ & Sobel & $\begin{array}{c}\text { Sum_ } \\
\text { Sigma }\end{array}$ & $\begin{array}{c}\text { GLCM } \\
\text { homo- } \\
\text { geneity }\end{array}$ & $\begin{array}{c}\text { GLCM } \\
\text { entropy }\end{array}$ \\
\hline agriculture/forest & 1.93 & 1.97 & 1.95 & 1.97 & 1.89 & 1.72 \\
forest/built-up & 1.41 & 1.01 & 1.00 & 1.02 & 0.96 & 1.30 \\
built-up/water & 1.68 & 1.98 & 1.99 & 1.99 & 1.03 & 1.70 \\
agriculture/built-up & 0.86 & 1.84 & 1.79 & 1.84 & 0.59 & 0.79 \\
forest/water & 2.00 & 2.00 & 2.00 & 2.00 & 2.00 & 2.00 \\
agriculture/water & 1.70 & 2.00 & 2.00 & 2.00 & 1.30 & 1.49 \\
\hline
\end{tabular}


Table 8

PAN data $-2 \mathrm{~m}$, Spain. Squared J-M distance between basic LC classes

\begin{tabular}{|l|c|c|c|c|c|c|}
\hline \multirow{2}{*}{ Land cover classes } & \multicolumn{7}{|c|}{ Texture functions } \\
\cline { 2 - 7 } & PanBF & $\begin{array}{c}\text { Laplace } \\
\text { 3x3 }\end{array}$ & Sobel & $\begin{array}{c}\text { Sum } \\
\text { Sigma }\end{array}$ & $\begin{array}{c}\text { GLCM } \\
\text { Homo- } \\
\text { geneity }\end{array}$ & $\begin{array}{c}\text { GLCM } \\
\text { Entropy }\end{array}$ \\
\hline agriculture/forest & 1.86 & 1.97 & 1.81 & 1.96 & 1.89 & 1.73 \\
forest/built-up & 1.57 & 1.02 & 0.99 & 1.07 & 1.06 & 1.41 \\
built-up/water & 1.64 & 1.99 & 1.99 & 1.99 & 1.19 & 1.70 \\
agriculture/built-up & 0.92 & 1.83 & 1.78 & 1.84 & 0.69 & 0.83 \\
forest/water & 2.00 & 2.00 & 2.00 & 2.00 & 2.00 & 2.00 \\
agriculture/water & 1.15 & 2.00 & 2.00 & 2.00 & 1.20 & 1.35 \\
\hline
\end{tabular}

Table 9

PAN data $-4 \mathrm{~m}$, Spain. Squared J-M distance between basic LC classes

\begin{tabular}{|l|c|c|c|c|c|c|}
\hline \multirow{2}{*}{ Land cover classes } & \multicolumn{6}{|c|}{ Texture functions } \\
\cline { 2 - 7 } & PanBF & $\begin{array}{c}\text { Laplace } \\
3 \times 3\end{array}$ & Sobel & $\begin{array}{c}\text { Sum_ } \\
\text { Sigma }\end{array}$ & $\begin{array}{c}\text { GLCM } \\
\text { homo- } \\
\text { geneity }\end{array}$ & $\begin{array}{c}\text { GLCM } \\
\text { entropy }\end{array}$ \\
\hline agriculture/forest & $\mathbf{1 . 7 5}$ & $\mathbf{1 . 9 2}$ & 1.36 & $\mathbf{1 . 9 0}$ & $\mathbf{1 . 8 5}$ & 1.63 \\
forest/built-up & 1.57 & 1.00 & 1.18 & 1.04 & 1.24 & 1.56 \\
built-up/water & 1.69 & $\mathbf{1 . 9 9}$ & $\mathbf{2 . 0 0}$ & $\mathbf{1 . 9 9}$ & 1.34 & 1.68 \\
agriculture/built-up & 1.02 & $\mathbf{1 . 8 1}$ & $\mathbf{1 . 8 3}$ & $\mathbf{1 . 8 3}$ & 0.83 & 0.87 \\
forest/water & $\mathbf{2 . 0 0}$ & $\mathbf{2 . 0 0}$ & $\mathbf{2 . 0 0}$ & $\mathbf{2 . 0 0}$ & $\mathbf{2 . 0 0}$ & $\mathbf{2 . 0 0}$ \\
agriculture/water & 0.96 & $\mathbf{2 . 0 0}$ & $\mathbf{2 . 0 0}$ & $\mathbf{2 . 0 0}$ & 0.90 & 0.91 \\
\hline
\end{tabular}

Table 10

PAN data $-8 \mathrm{~m}$, Spain. Squared J-M distance between basic LC classes

\begin{tabular}{|l|c|c|c|c|c|c|}
\hline \multirow{2}{*}{ Land cover classes } & \multicolumn{6}{|c|}{ Texture functions } \\
\cline { 2 - 7 } & PanBF & $\begin{array}{c}\text { Laplace } \\
3 \times 3\end{array}$ & Sobel & $\begin{array}{c}\text { Sum_ } \\
\text { Sigma }\end{array}$ & $\begin{array}{c}\text { GLCM } \\
\text { homo- } \\
\text { geneity }\end{array}$ & $\begin{array}{c}\text { GLCM } \\
\text { entropy }\end{array}$ \\
\hline agriculture/forest & 1.53 & $\mathbf{1 . 7 8}$ & 1.09 & $\mathbf{1 . 7 7}$ & 1.66 & 1.51 \\
forest/built-up & 1.40 & 1.03 & 1.34 & 1.09 & 1.27 & 1.63 \\
built-up/water & 1.60 & $\mathbf{1 . 9 9}$ & $\mathbf{2 . 0 0}$ & $\mathbf{2 . 0 0}$ & 1.33 & 1.65 \\
agriculture/built-up & 1.04 & $\mathbf{1 . 8 5}$ & $\mathbf{1 . 8 0}$ & $\mathbf{1 . 8 7}$ & 0.89 & 1.06 \\
forest/water & $\mathbf{2 . 0 0}$ & $\mathbf{2 . 0 0}$ & $\mathbf{2 . 0 0}$ & $\mathbf{2 . 0 0}$ & $\mathbf{2 . 0 0}$ & $\mathbf{2 . 0 0}$ \\
agriculture/water & 0.66 & $\mathbf{2 . 0 0}$ & $\mathbf{1 . 9 9}$ & $\mathbf{2 . 0 0}$ & 0.66 & 0.48 \\
\hline
\end{tabular}


Table 11

PAN data $-16 \mathrm{~m}$, Spain. Squared J-M distance between basic LC classes

\begin{tabular}{|l|c|c|c|c|c|c|}
\hline \multirow{2}{*}{ Land cover classes } & \multicolumn{6}{|c|}{ Texture functions } \\
\cline { 2 - 7 } & PanBF & $\begin{array}{c}\text { Laplace } \\
3 \times 3\end{array}$ & Sobel & $\begin{array}{c}\text { Sum- } \\
\text { Sigma }\end{array}$ & $\begin{array}{c}\text { GLCM } \\
\text { homo- } \\
\text { geneity }\end{array}$ & $\begin{array}{c}\text { GLCM } \\
\text { entropy }\end{array}$ \\
\hline agriculture/forest & 0.87 & 1.62 & 0.45 & 1.58 & 0.86 & 1.12 \\
forest/built-up & 1.19 & 1.22 & 1.22 & 1.22 & 1.14 & 1.53 \\
built-up/water & 1.60 & 2.00 & 1.99 & 2.00 & 1.26 & 1.58 \\
agriculture/built-up & 0.82 & 1.91 & 1.47 & 1.89 & 0.73 & 1.22 \\
forest/water & 2.00 & 2.00 & 2.00 & 2.00 & 1.99 & 2.00 \\
agriculture/water & 0.38 & 2.00 & 1.85 & 2.00 & 0.41 & 0.57 \\
\hline
\end{tabular}

Table 12

PAN data $-1 \mathrm{~m}$. Squared J-M distance between the combined classes:

(i) "water" and "agriculture areas", and (ii) "forest" and "built-up areas"

\begin{tabular}{|l|c|c|c|c|c|c|}
\hline \multirow{2}{*}{ Country } & \multicolumn{6}{|c|}{ Texture functions } \\
\cline { 2 - 7 } & PanBF & $\begin{array}{c}\text { Laplace } \\
3 \times 3\end{array}$ & Sobel & $\begin{array}{c}\text { Sum } \\
\text { Sigma }\end{array}$ & $\begin{array}{c}\text { GLCM } \\
\text { homo- } \\
\text { geneity }\end{array}$ & $\begin{array}{c}\text { GLCM } \\
\text { entropy }\end{array}$ \\
\hline Poland & $\mathbf{1 . 9 0}$ & $\mathbf{1 . 9 2}$ & $\mathbf{1 . 9 2}$ & $\mathbf{1 . 9 2}$ & 1.38 & $\mathbf{1 . 8 3}$ \\
Germany & $\mathbf{1 . 7 4}$ & $\mathbf{1 . 9 2}$ & $\mathbf{1 . 9 6}$ & $\mathbf{1 . 9 2}$ & 0.91 & $\mathbf{1 . 7 2}$ \\
Finland & 1.59 & $\mathbf{1 . 9 1}$ & $\mathbf{1 . 9 5}$ & $\mathbf{1 . 9 1}$ & 1.05 & 1.54 \\
France & $\mathbf{1 . 8 4}$ & $\mathbf{1 . 8 2}$ & $\mathbf{1 . 7 9}$ & $\mathbf{1 . 8 1}$ & 0.95 & $\mathbf{1 . 7 3}$ \\
Spain & 1.60 & 1.63 & 1.62 & 1.62 & 1.18 & 1.35 \\
\hline
\end{tabular}

Table 13

PAN data $-2 \mathrm{~m}$. Squared J-M distance between the combined classes:

(i) "water" and "agriculture areas", and (ii) "forest" and "built-up areas"

\begin{tabular}{|l|c|c|c|c|c|c|}
\hline \multirow{2}{*}{ Country } & \multicolumn{6}{|c|}{ Texture functions } \\
\cline { 2 - 7 } & PanBF & $\begin{array}{c}\text { Laplace } \\
3 \times 3\end{array}$ & Sobel & $\begin{array}{c}\text { Sum } \\
\text { Sigma }\end{array}$ & $\begin{array}{c}\text { GLCM } \\
\text { homo- } \\
\text { geneity }\end{array}$ & $\begin{array}{c}\text { GLCM } \\
\text { entropy }\end{array}$ \\
\hline Poland & $\mathbf{1 . 8 1}$ & $\mathbf{1 . 9 2}$ & $\mathbf{1 . 8 2}$ & $\mathbf{1 . 9 1}$ & 1.44 & $\mathbf{1 . 7 8}$ \\
Germany & 1.65 & $\mathbf{1 . 9 5}$ & $\mathbf{1 . 9 2}$ & $\mathbf{1 . 9 5}$ & 1.10 & $\mathbf{1 . 7 2}$ \\
Finland & 1.57 & $\mathbf{1 . 9 5}$ & $\mathbf{1 . 8 7}$ & $\mathbf{1 . 9 5}$ & 1.15 & 1.54 \\
France & $\mathbf{1 . 7 3}$ & $\mathbf{1 . 8 1}$ & 1.68 & $\mathbf{1 . 7 7}$ & 1.06 & 1.68 \\
Spain & 1.61 & 1.64 & 1.48 & 1.60 & 1.06 & 1.38 \\
\hline
\end{tabular}


Table 14

PAN data $-4 \mathrm{~m}$. Squared J-M distance between the combined classes:

(i) "water" and "agriculture areas", and (ii) "forest" and "built-up areas"

\begin{tabular}{|l|c|c|c|c|c|c|}
\hline \multirow{2}{*}{ Country } & \multicolumn{5}{|c|}{ Texture functions } \\
\cline { 2 - 7 } & PanBF & $\begin{array}{c}\text { Laplace } \\
3 \times 3\end{array}$ & Sobel & $\begin{array}{c}\text { Sum } \\
\text { Sigma }\end{array}$ & $\begin{array}{c}\text { GLCM } \\
\text { homo- } \\
\text { geneity }\end{array}$ & $\begin{array}{c}\text { GLCM } \\
\text { entropy }\end{array}$ \\
\hline Poland & 1.60 & $\mathbf{1 . 8 4}$ & 1.22 & $\mathbf{1 . 7 9}$ & 1.51 & 1.48 \\
Germany & 1.61 & $\mathbf{1 . 8 9}$ & 1.32 & $\mathbf{1 . 8 4}$ & 1.36 & 1.61 \\
Finland & 1.60 & $\mathbf{1 . 8 0}$ & 1.18 & $\mathbf{1 . 7 7}$ & 1.45 & 1.44 \\
France & 1.57 & $\mathbf{1 . 7 5}$ & 1.38 & 1.67 & 1.25 & 1.61 \\
Spain & 1.60 & 1.60 & 1.13 & 1.54 & 1.03 & 1.48 \\
\hline
\end{tabular}

Table 15

PAN data $-8 \mathrm{~m}$. Squared J-M distance between the combined classes:

(i) "water" and "agriculture areas", and (ii) "forest" and "built-up areas"

\begin{tabular}{|l|c|c|c|c|c|c|}
\hline \multirow{2}{*}{ Country } & \multicolumn{5}{|c|}{ Texture functions } \\
\cline { 2 - 7 } & PanBF & $\begin{array}{c}\text { Laplace } \\
3 \times 3\end{array}$ & Sobel & $\begin{array}{c}\text { Sum- } \\
\text { Sigma }\end{array}$ & $\begin{array}{c}\text { GLCM } \\
\text { homo- } \\
\text { geneity }\end{array}$ & $\begin{array}{c}\text { GLCM } \\
\text { entropy }\end{array}$ \\
\hline Poland & 1.27 & 1.21 & 0.25 & 1.09 & 1.34 & 0.76 \\
Germany & 1.40 & 1.14 & 0.57 & 1.03 & 1.47 & 1.23 \\
Finland & 1.40 & 1.03 & 0.54 & 0.97 & 1.59 & 1.23 \\
France & 1.32 & 1.65 & 1.18 & 1.56 & 1.25 & 1.56 \\
Spain & 1.45 & 1.45 & 0.93 & 1.43 & 1.10 & 1.57 \\
\hline
\end{tabular}

Table 16

PAN data $-16 \mathrm{~m}$. Squared J-M distance between the combined classes:

(i) "water" and "agriculture areas", and (ii) "forest" and "built-up areas"

\begin{tabular}{|l|c|c|c|c|c|c|}
\hline \multirow{2}{*}{ Country } & \multicolumn{6}{|c|}{ Texture functions } \\
\cline { 2 - 7 } & PanBF & $\begin{array}{c}\text { Laplace } \\
3 \times 3\end{array}$ & Sobel & $\begin{array}{c}\text { Sum } \\
\text { Sigma }\end{array}$ & $\begin{array}{c}\text { GLCM } \\
\text { homo- } \\
\text { geneity }\end{array}$ & $\begin{array}{c}\text { GLCM } \\
\text { entropy }\end{array}$ \\
\hline Poland & 0.39 & 0.33 & 0.02 & 0.24 & 0.77 & 0.15 \\
Germany & 0.75 & 0.52 & 0.03 & 0.45 & 1.08 & 0.64 \\
Finland & 1.06 & 0.54 & 0.17 & 0.49 & 1.51 & 1.11 \\
France & 0.94 & 1.41 & 0.91 & 1.37 & 0.96 & 1.36 \\
Spain & 1.26 & 1.26 & 0.56 & 1.23 & 1.09 & 1.53 \\
\hline
\end{tabular}


niques decreased the ability to distinguish land types. As before, in the case of the image from Spain, the division into low and high texture was impossible.

The results for the $4 \mathrm{~m}$ resolution are presented in Table 14. By far the best results were obtained for the Laplace filter followed by the Lee Sigma. In the case of France the J-M distance obtained from the Lee Sigma filter was below the accepted threshold of 1.7. As before, the Spanish image could not be analysed, and a further increase in pixel size to $8 \mathrm{~m}$, followed by $16 \mathrm{~m}$, resulted in a complete lack of distinction (see Tables 15 and 16, respectively).

The results of the analysis of the images from Poland, Germany, and Finland were similar although none were as good as the image from France. As we have highlighted, the worst results were obtained for Spain. Therefore, we argue that a classification approach based on low and high texture can be applied in Northern, Central, and Eastern Europe. However, this approach is not effective in Southern Europe because the land cover structure is different.

Figure 5 illustrates the distinction between land cover classes based on German test site images processed by a Laplacian $3 \times 3$ filter. The training sets are represented by the corresponding normal distributions. In the case of the $1 \mathrm{~m}$ resolution (Fig. 5a), the values for "water bodies" and "agricultural areas" completely overlap. The same is seen for "forest" and "built-up areas". We can therefore assume that a threshold between low and high texture can be defined at a value of about 45 . In the case of images with a resolution of $8 \mathrm{~m}$ (Fig. 5b), such a division is not possible, because "agricultural areas" overlap with "forest" and (unlike at $1 \mathrm{~m}$ resolution) it is impossible to divide

(a)
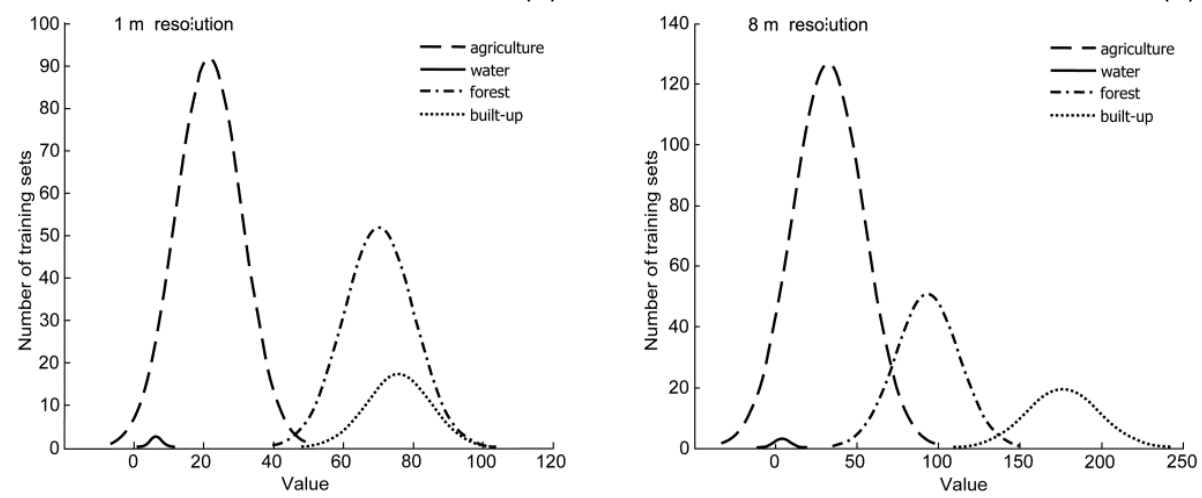

Fig. 5. Graphical analyses of the separation of land cover classes (German test site) at $1 \mathrm{~m} \mathrm{(a)}$ and $8 \mathrm{~m}$ (b) resolutions. 
(a)

(b)
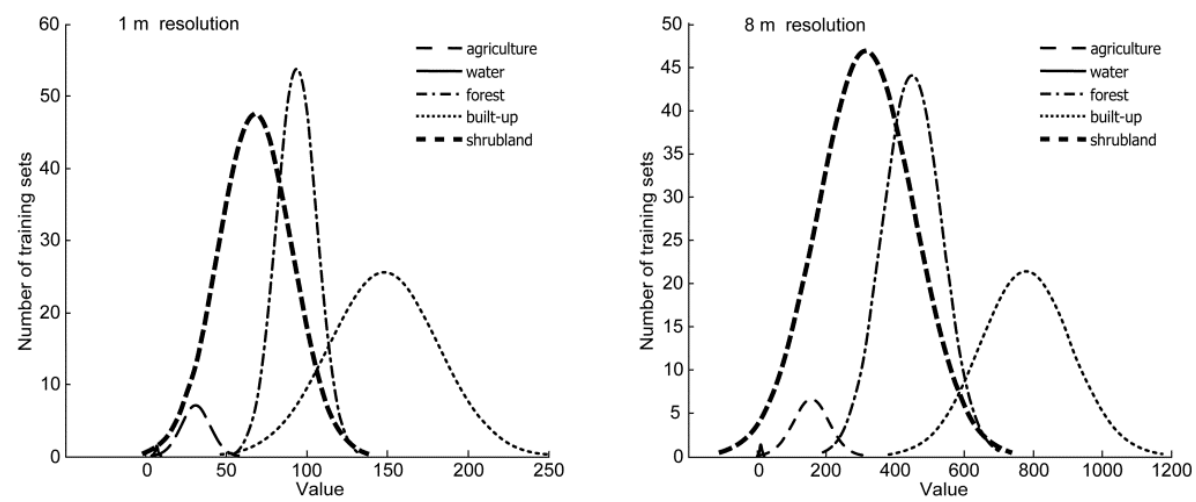

Fig. 6. Graphical analyses of the separation of land cover classes (Spanish test site) at $1 \mathrm{~m}$ (a) and $8 \mathrm{~m}$ (b) resolutions.

the image into two parts. Figure 6 shows the distribution of classes in Spain, and highlights the marked presence of the "shrubland" land cover class. This class occurs frequently in the South of Europe and must be taken into account in the classification process. "Shrubland" overlaps with "water bodies", "agricultural areas", "forest", and large parts of "built-up areas". The result is that an unequivocal division into low and high texture is impossible.

\section{CONCLUSIONS}

The basic division into low and high textures in the initial stage of the classification procedure enables a qualitative comparison of features. The feature space distances were calculated from the J-M distance between pairs of land cover classes: water bodies, agricultural areas, forest, built-up areas, and shrubland (dispersed vegetation). These classes were selected as the best representatives of low and high texture. An evaluation of the quality of results was performed at an early stage of the classification process, which helped to accurately trace the exact relationships between land cover classes.

Texture values depend on the function used, the spatial resolution of the image (pixel size) and the size of the land cover feature. We assumed that in the European context the size of land cover objects at the test sites were comparable. Any differences were primarily due to the density of vegetation and construction. Although similar results were obtained for the sites located in Poland, Germany, Finland, and France, the results from the Spanish test site were different.

Of the six texture feature functions we analysed, the best results were obtained with the Laplacian $3 \times 3$ filter, followed by the Sum of Lee Sigma and 
PanBF functions. These texture functions made it possible to separate "water bodies" and "agricultural areas" from "forest" and "built-up areas". Much poorer results were obtained using GLCM homogeneity and entropy.

The classification approach based on low and high texture can be applied to panchromatic images with resolutions of 1,2 , and $4 \mathrm{~m}$. The correctness of results decreases as the pixel size increases. Because of this, the classification should not be attempted on images with a resolution equal to or higher than $8 \mathrm{~m}$. For such large pixels the threshold cannot be defined properly because the basic land cover classes cannot be properly distinguished.

The results from the Spanish site show that when land cover classes representing low and high texture overlap, it is practically impossible to divide them. This can be due to landscape features such as vegetation, topography, and climate. Even at a $1 \mathrm{~m}$ resolution, the distribution of "forest" that is not overlapped by "built-up areas" is misclassified as "agriculture". In addition to these areas, a highly dispersed "shrubland" class occurs. This class fully overlaps with both "agricultural areas" and "forest", which makes it difficult to perform a proper classification. Therefore, algorithms based on low and high texture can be used successfully mainly in Northern, Central, and Eastern Europe. Applying the technique to satellite images of Southern Europe is problematic if dispersed vegetation dominates, or if it affects the classification results.

Acknowledgements. Our research was carried out in the context of the SATChMo/Geoland2 FP7 project. Our analyses were performed with the kind help of: Astrium GEO-Information Services - Infoterra Ltd., Leicester, UK; the Finnish Environment Institute SYKE, Helsinki, Finland; the German Aerospace Center (DLR); the German Remote Sensing Data Center (DFD), Oberpfaffenhofen, Germany; the Institute of Aerial Geodesy, Applied Research Center, Kaunas, Lithuania; the Institute of Geodesy and Cartography, Warsaw, Poland; Specto Natura Ltd., Cambridge, UK; the University of Osnabrück, Institute for Geoinformatics and Remote Sensing (IGF), Osnabrück, Germany.

Earth Observation data was provided by the GSC-DA project managed by the European Space Agency and funded by the European Community's Seventh Framework Programme (FP7/2007-2013) under EC-ESA Grant Agreement No. 223001.

The authors would like to thank Roeland de Kok for inspiration, discussion, and critical remarks. 


\section{References}

Berberoglu, S., P.J. Curran, C.D. Lloyd, and P.M. Atkinson (2007), Texture classification of Mediterranean land cover, Int. J. Appl. Earth Observ. Geoinf. 9, 3, 322-334, DOI: 10.1016/ j.jag.2006.11.004.

Blaschke, T. (2010), Object based image analysis for remote sensing, ISPRS J. Photogramm. Remote Sens. 65, 1, 2-16, DOI: 10.1016/j.isprsjprs.2009. 06.004.

De Kok, R. (2012), Spectral difference in the image domain for large neighborhoods, a GEOBIA pre-processing step for high resolution imagery, Remote Sens. 4, 8, 2294-2313, DOI: 10.3390/rs4082294.

De Kok, R., and P. Wezyk (2008), Principles of full autonomy in image interpretation. The basic architectural design for a sequential process with image objects. In: Th. Blaschke, S. Lang, and G.J. Hay (eds.), Object-Based Image Analysis: Spatial Concepts for Knowledge-Driven Remote Sensing Applications, Lecture Notes in Geoinformation and Cartography, Springer, Berlin Heidelberg, 697-710, DOI: 10.1007/978-3-540-77058-9_38.

De Martinao, M., F. Causa, and S.B. Serpico (2003), Classification of optical high resolution images in urban environment using spectral and textural information. In: Proc. IEEE Int. Symp. Geoscience and Remote Sensing IGARSS'03, 21-25 July 2003, Toulouse, France, DOI: 10.1109/IGARSS. 2003.1293811.

Eckert, S. (2012), Improved forest biomass and carbon estimations using texture measures from WorldView-2 satellite data, Remote Sens. 4, 4, 810-829, DOI: $10.3390 /$ rs4040810.

eCognition Developer (2011), eCognition Developer, Reference book, Trimble documentation, Munich, Germany.

Esch, T., M. Thiel, A. Schenk, A. Roth, A. Muller, and S. Dech (2010), Delineation of urban footprints from TerraSAR-X data by analyzing speckle characteristics and intensity information, IEEE Trans. Geosci. Remote Sens. 48, 2, 905-916, DOI: 10.1109/TGRS.2009.2037144.

Hall-Beyer, M. (2000), GLCM texture: a tutorial, Department of Geography, University of Calgary, Calgary, Canada, http://www.fp.ucalgary.ca/mhallbey/ tutorial.htm.

Haralick, R.M., K. Shanmugan, and I. Dinstein (1973), Textural features for image classification, IEEE Trans. Syst. Man Cybernetics SMC-3, 6. 610-621, DOI: 10.1109/TSMC.1973.4309314.

He, C., J. Li, J. Zhang, Y. Pan, and Y. Chen (2005), Dynamic monitor on urban expansion based on a object-oriented approach. In: Proc. IEEE Int. Symp. Geoscience and Remote Sensing IGARSS'05, 25-29 July 2005, Seoul, Korea, 2850-2853, DOI: 10.1109/IGARSS.2005.1525662.

Hofmann, T., J. Puzicha, and J.M. Buhmann (1998), Unsupervised texture segmentation in a deterministic annealing framework, IEEE Trans. Pattern Anal. Mach. Intellig. 20, 8, 803-818, DOI: 10.1109/34.709593. 
Hu, X., C.V. Tao, and B. Prenzel (2005), Automatic segmentation of high-resolution satellite imagery by integrating texture, intensity, and colour features, Photogramm Eng. Rem. Sens. 71, 12, 1399-1406, DOI: 10.14358/PERS. 71.12. 1399.

Intergraph (1999), Image Analyst User's Guide for Windows, Intergraph Corporation, Huntsville, USA.

Jain, A.K. (1989), Fundamentals of Digital Image Processing, Prentice-Hall, Englewood Cliffs, 569 pp.

Jensen, J.R. (1996), Introductory Digital Image Processing: A Remote Sensing Perspective, 2nd ed., Prentice Hall, Upper Saddle River, 316 pp.

Kit, O., M. Lüdeke, and D. Reckien (2012), Texture-based identification of urban slums in Hyderabad, India using remote sensing data, Appl. Geogr. 32, 2, 660-667, DOI: 10.1016/j.apgeog.2011.07.016.

Lewinski, S., and Z. Bochenek (2009), Rule-based classification of SPOT imagery using object-oriented approach for detailed land cover mapping. In: Proc. 28th EARSeL Symp. "Remote Sensing for a Changing Europe", 2-5 June 2008, Istanbul, Turkey.

Lewinski, S., Z. Bochenek, and K. Turlej (2014), Application of an object-oriented method for classification of VHR satellite images using rule-based approach and texture measures. In: I. Manakos and M. Braun (eds.), Land Use and Land Cover Mapping in Europe: Practices and Trends, Remote Sensing and Digital Image Processing, Vol. 18, 193-201, Springer Science + Business Media, Dordrecht, DOI: 10.1007/978-94-007-7969-3_12.

Morales, D.I., M. Moctezuma, and F. Parmiggiani (2003), Urban and non urban area classification by texture characteristics and data fusion. In: Proc. IEEE Int. Symp. Geoscience and Remote Sensing IGARSS'03, 21-25 July 2003, Toulouse, France, 3504-3506, DOI: 10.1109/IGARSS.2003.1294835.

Murray, H., A. Lucieer, and R. Williams (2010), Texture-based classification of subAntarctic vegetation communities on Heard Island, Int. J. Appl. Earth Observ. Geoinform. 12, 3, 138-149, DOI: 10.1016/j.jag.2010.01.006.

Nussbaum, S., I. Niemeyer, and M.J. Canty (2006), SEaTH - A new tool for automated feature extraction in the context of object-based image analysis. In: Proc. 1st Int. Conf. on Object-based Image Analysis (OBIA), 4-5 July 2006, Salzburg, Austria.

Puissant, A., J. Hirsch, and C. Weber (2005), The utility of texture analysis to improve per-pixel classification for high to very high spatial resolution imagery, Int. J. Remote Sens. 26, 4, 733-745, DOI: 10.1080/ 01431160512331316838.

Ryherd, S., and C. Woodcock (1996), Combining spectral and texture data in the segmentation of remotely sensed images, Photogramm. Eng. Remote Sens. 62, 2, 181-194.

Su, W., J. Li, Y. Chen, Z. Liu, J. Zhang, T.M. Low, I. Suppiah, and S.A.M. Hashim (2008), Textural and local spatial statistics for the object-oriented classifi- 
cation of urban areas using high resolution imagery, Int. J. Remote Sens. 29, 11, 3105-3117, DOI: 10.1080/01431160701469016.

Thomas, V., P. Treitz, D. Jelinski, J. Miller, P. Lafleur, and J.H. McCaughey (2003), Image classification of a northern peatland complex using spectral and plant community data, Remote Sens Environ. 84, 1, 83-99, DOI: 10.1016/ S0034-4257(02)00099-8.

Tuceryan, M., and A.K. Jain (1999), Texture analysis. In: C.H. Chen, L.F. Pau, and P.S.P. Wang (eds.), The Handbook of Pattern Recognition and Computer Vision, 2nd ed., World Scientific Publ. Co., Singapore, 207-248.

Wang, Y.W., Y.F. Wang, Y. Xue, and W. Gao (2003), A new algorithm for remotely sensed image texture classification and segmentation. In: Proc. IEEE Int. Symp. Geoscience and Remote Sensing IGARSS'03, 21-25 July 2003, Toulouse, France, 3534-3536, DOI: 10.1109/IGARSS.2003. 1294845.

Wezyk, P., and R. De Kok (2006), Automatic mapping of the dynamics of forest succession on abandoned parcels in south Poland. In: J. Strobl, T. Blaschke, and G. Griesebner (eds.), Angewandte Geoinformatik 2005, Wichman Verlag, Heidelberg, 774-779 (in German).

Received 27 June 2014

Accepted 23 September 2014 